\title{
COVID-19: Once in a Century Health Challenge
}

Sakhawat Ali Randhawa

COVID-19 has changed the mode of living. World is currently facing an outbreak of historic proportions. In a matter of weeks, the corona virus has reached over 190 countries and according to World Health Organization, on the end of March 2020, there are about 750890 new cases of COVID 19 and 36405 deaths, reported globally. 1 The virus is spreading fast, and it does not look like that it will eliminate soon.

Most of us have already witnessed firsthand how this affects our society. This challenge is not like a storm, it is more like a season, and that season has just begun, in our country. This situation will be thought about and written about for decades to come. It puts us all in a position to reconsider our habits and ask ourselves what we can do to stay safe, protect our loved ones, and slow down the spread. That is a lot to ask, but I think we can better step up to this challenge if we decide to live out this moment as an ordinary hero. It is a simple mental device that will slow down mindless choices, and allow you to put your deepest yearnings into your life during this pandemic. If you turn on an idiot box (phone, laptop, or television), you will learn something crazy.

Although donors and WHO are working intensively with partners to increase access to lifesaving products, including diagnostics, PPE, medical oxygen, ventilators and more, there is still a lot to do.2 When hospitals become overburdened then patients will not receive adequate treatment. Medical equipment becomes sparse. Our healthcare system is finite with limited resources. This may lead to thousands of thousands of preventable deaths. We need to slow down the spread of the virus so that hospitals and healthcare facilities are able to catch up with the growing demand for medical attention. The more we slow down the outbreak, the better hospitals are able to attend to those in need. If we want to prevent unnecessary deaths, we need to take effective action here and now. Every action is being written down in history. The fate of us and our loved ones depends on the choices we make, moment by moment, day by day.

The important thing to do right now is to create social distance - to stay home, only go out if necessary, and cancel all social events. Stock up only what is needed (e.g., for two weeks, not three months). Go out as little as possible, this is not only sensible, but it is also kind and responsible. Every one of us is authoring this script.

Hand washing is still one of the most effective things we can do to protect ourselves from catching the virus. We need to do it regularly, thoroughly and for at least 20 seconds. Do not touch your face, and avoid shaking hands and hugging other people. Keep a running tally of every single time you touch your face. It is important to become conscious of it. In the middle of this outbreak, a lot of people will feel scared, lonely, and isolated. Now is a good time to call friends or family, let them know you care about them and be there for one another.3

People are going hungry. If you wish to donate to help vulnerable people in need. Stay safe, stay healthy, and stay socially distanced. Your actions are being noticed anonymously by people you will never meet for whom the reduced demand for hospital beds may be a matter of life and death. 
Although the older people with co-morbidity are the hardest hit but younger people are also not spared. This virus can put youngsters in hospital for weeks, or even kill them. The choices we make can be of vital importance and could be the difference between life and death.

Dr. Sakhawat Ali Randhawa
MBBS; MCPS-HCSM; FELTP
Chief Executive Officer, District Health Authority,
Rahim Yar Khan.
Email: drrandhawa7@yahoo.com

